\title{
Underweight and mortality
}

\section{Citation}

Lee, Joo Young, Hyeon Chang Kim, Changsoo Kim, Keeho Park, Song Vogue Ahn, Dae Ryong Kang, Kay-Tee Khaw, Walter C Willett, and II Suh. 2015. "Underweight and Mortality." Public Health Nutrition 19 (10): 1751-56. https://doi.org/10.1017/s136898001500302x.

\section{Permanent link}

http://nrs.harvard.edu/urn-3:HUL.InstRepos:41426788

\section{Terms of Use}

This article was downloaded from Harvard University's DASH repository, and is made available under the terms and conditions applicable to Other Posted Material, as set forth at http:// nrs.harvard.edu/urn-3:HUL.InstRepos:dash.current.terms-of-use\#LAA

\section{Share Your Story}

The Harvard community has made this article openly available.

Please share how this access benefits you. Submit a story.

\section{Accessibility}




\title{
Underweight and mortality
}

\author{
Joo Young Lee ${ }^{1}$, Hyeon Chang Kim ${ }^{1}$, Changsoo Kim ${ }^{1}$, Keeho Park², Song Vogue Ahn ${ }^{3}$, \\ Dae Ryong Kang ${ }^{4}$, Kay-Tee Khaw ${ }^{5}$, Walter C Willett ${ }^{6}$ and II Suh ${ }^{1, *}$ \\ 'Department of Preventive Medicine, Yonsei University College of Medicine, 50-1 Yonsei-ro, Seodaemun-gu, Seoul \\ 120-752, Republic of Korea: ${ }^{2}$ Cancer Policy Branch, National Cancer Center, Ilsan-ro, Ilsandong-gu, Gyeonggi-do, \\ Republic of Korea: ${ }^{3}$ Department of Preventive Medicine, Yonsei University Wonju College of Medicine, \\ Gangwon-do, Republic of Korea: ${ }^{4}$ Office of Biostatistics, Ajou University School of Medicine, Suwon, Republic of \\ Korea: ${ }^{5}$ Clinical Gerontology Unit, Addenbrookes' Hospital, University of Cambridge, Cambridge, UK: \\ ${ }^{6}$ Departments of Nutrition and Epidemiology, Harvard School of Public Health, Boston, MA, USA
}

Submitted 30 April 2015: Final revision received 4 September 2015: Accepted 23 September 2015: First published online 15 0ctober 2015

\begin{abstract}
Objective: According to most prospective studies, being underweight (BMI $<18.5$ $\mathrm{kg} / \mathrm{m}^{2}$ ) is associated with significantly higher mortality than being of normal weight, especially among smokers. We aimed to explore in a generally lean population whether being underweight is significantly associated with increased all-cause mortality.

Design: Prospective cohort study.

Setting: Korea Medical Insurance Corporation study with 14 years of follow-up.

Subjects: After excluding deaths within the first 5 years of follow-up (1993-1997) to minimize reverse causation and excluding participants without information about smoking and health status, 94133 men and 48496 women aged 35-59 years in 1990 were included.

Results: We documented $5411(5.7 \%)$ deaths in men and $762(1.6 \%)$ in women. Among never smokers, hazard ratios (HR) for underweight individuals were not significantly higher than those for normal-weight individuals $\left(B M I=18.5-22.9 \mathrm{~kg} / \mathrm{m}^{2}\right)$ : $\mathrm{HR}=0.87(95 \% \mathrm{CI} 0.41,1.84, P=0.72)$ for underweight men and $\mathrm{HR}=1.12(95 \% \mathrm{CI}$ $0 \cdot 76,1.65, P=0.58)$ for underweight women. Among ex-smokers, HR=0.86 (95\% CI $0.38,1.93, P=0.72$ ) for underweight men and $\mathrm{HR}=3.77$ (95\% CI $0.42,32.29$, $P=0.24$ ) for underweight women. Among current smokers, HR=1.60 (95\% CI 1.28 , $2 \cdot 01, P<0.001)$ for underweight men and $\mathrm{HR}=2.07$ (95\% CI 0.43, 9.94, $P=0.36$ ) for underweight women.

Conclusions: The present study does not support that being underweight per se is associated with increased all-cause mortality in Korean men and women.
\end{abstract}

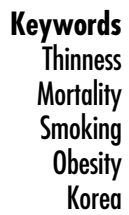

and other infectious diseases is low. Therefore we aimed to investigate the associations between being underweight and mortality in Korean men and women.

\section{Methods}

\section{Study population}

The Korea Medical Insurance Corporation (KMIC) provides health insurance to civil service workers, teachers and their dependants in Korea. Of the entire Korean population (approximately 43 million in 1990), 4603361 (11\%) were insured by KMIC, including 1213594 workers and 3389767 dependants. All insured workers are required to participate in biennial medical examinations performed by KMIC. In 1990 and 1992, respectively 95\% and 94\% of workers 
completed the biennial examinations. The KMIC study comprised a $25 \%$ systematic random sample of male workers and all female workers, drawn from insured members ordered by national identification numbers. The study comprised 108461 men and 64119 women, aged 35-59 years, who underwent physical examinations twice in 1990 and 1992. Ethical approval was given by the Institutional Review Board of Severance Hospital at Yonsei University.

\section{Measurements}

The KMIC biennial examinations were conducted in a standardized fashion by medical staff at local hospitals. In 1990, examinations were conducted at 416 hospitals. A questionnaire was administered to each participant three to four days before physical examination, and completed questionnaires were reviewed and edited by trained staff. Smoking history, alcohol consumption, physical activity and health status were assessed in 1992. Age was documented in 1990. Height, weight, fasting glucose, total cholesterol, systolic blood pressure and diastolic blood pressure were measured in 1990 and 1992, and were averaged for analysis. BMI was calculated as weight in kilograms divided by the square of height in metres $\left(\mathrm{kg} / \mathrm{m}^{2}\right)$. BMI groups were divided according to the WHO recommendations for Asians: underweight, $<18.5 \mathrm{~kg} / \mathrm{m}^{2}$; normal range, $18.5-22.9 \mathrm{~kg} / \mathrm{m}^{2}$; overweight at risk, $23.0-24.9 \mathrm{~kg} / \mathrm{m}^{2}$; obese I, $25 \cdot 0-29 \cdot 9 \mathrm{~kg} / \mathrm{m}^{2}$; and obese II, $\geq 30 \cdot 0 \mathrm{~kg} / \mathrm{m}^{2(21)}$. Participants were classified as current smokers if they were smoking, ex-smokers if they smoked at least one cigarette during their whole life but quit, and never smoker if they never smoked even one cigarette.

\section{Mortality follow-up}

The follow-up period, which lasted 14 years, was from 1 January 1993 to 31 December 2006. Death certificates from the National Statistical Office were issued according to identification numbers that were assigned to the participants at birth. The causes of death were coded according to the International Classification of Diseases, 10th revision (ICD-10): CVD were categorized by ICD-10 codes I00-I99; cancers were classified by ICD-10 codes C00-C97; and respiratory diseases were coded by ICD-10 codes J00-J99. Other causes of deaths were defined as deaths from other causes than cardiovascular, cancer and respiratory causes.

\section{Statistical analysis}

We excluded 8317 men and 4561 women who had known diseases at baseline, and further excluded 2041 men and 329 women who died during 1993-1997 to minimize the impact of reverse causality. We also excluded 3970 men and 10733 women who had no information on smoking. Finally, we included 94133 men and 48496 women for analysis. All statistical analyses were performed separately for men and women. Baseline characteristics of the participants are listed according to BMI categories. Cox's proportional hazards regression models were used to calculate hazard ratios (HR) and $95 \%$ CI to investigate the association between BMI and all-cause mortality after adjusting for age and alcohol consumption. In order to investigate whether being underweight is associated with all-cause mortality independently from smoking status, we calculated HR and 95\% CI separately for never smokers, ex-smokers and current smokers. The Cox's regression models were adjusted for age, alcohol consumption and cigarettes smoked per day (only for current smokers). As an exploratory analysis, we also calculated HR and 95\% CI for cause-specific mortality: CVD, cancer, respiratory disease and other causes. All statistical procedures were performed using the statistical software package SAS version 9.2 and all $P$ values less than 0.05 were considered statistically significant.

\section{Results}

The general characteristics of the study participants are presented according to BMI category in Table 1. For men, the numbers of individuals in each BMI group $\left(<18.5 \mathrm{~kg} / \mathrm{m}^{2}, \quad 18.5-22.9 \mathrm{~kg} / \mathrm{m}^{2}, \quad 23.0-24.9 \mathrm{~kg} / \mathrm{m}^{2}\right.$, $\left.25 \cdot 0-29.9 \mathrm{~kg} / \mathrm{m}^{2}, \geq 30 \cdot 0 \mathrm{~kg} / \mathrm{m}^{2}\right)$ were $974(1.0 \%), 40254$ (42.8\%), 29369 (31.2\%), 22946 (24.4\%) and 590 (0.6\%), respectively. For women, the numbers in those groups were 2199 (4.5\%), 29209 (60.2\%), 11028 (22.7\%), 5841 $(12.0 \%)$ and $219(0.5 \%)$, respectively. Male participants who were underweight had relatively lower mean values for blood pressure, fasting glucose and total cholesterol; they were also more likely to be current smokers, nondrinkers and physically inactive, compared with those in higher BMI categories. Female participants who were underweight had relatively lower mean age, blood pressure, fasting glucose and total cholesterol; they were also more likely to be non-drinkers and physically inactive, compared with women in higher BMI categories.

In Table 2, analyses adjusted for age and alcohol consumption revealed a significantly higher $\mathrm{HR}$ for total mortality in underweight men ( $\mathrm{HR}=1.48$; $95 \% \mathrm{CI} 1 \cdot 21,1 \cdot 82)$ compared with individuals with normal BMI. Men in the obese II category were also associated with higher all-cause mortality (HR $=1.28 ; 95 \%$ CI 0.96, 1.70) compared with those with normal BMI, although the association was not statistically significant. Underweight ( $\mathrm{HR}=1.20 ; 95 \% \mathrm{CI} 0.83,1.74)$ and obese II $(\mathrm{HR}=1.55 ; 95 \%$ CI $0.73,3.29)$ women showed higher mortality than women with normal BMI, although these associations were not statistically significant.

In Table 3 we present the HR for all-cause mortality among the BMI groups stratified according to smoking status, with adjustment for age and alcohol consumption. The reference group comprised participants with normal BMI within the same stratum of smoking status. Among male never smokers, being underweight was not associated with all-cause mortality $(\mathrm{HR}=0 \cdot 87 ; 95 \%$ CI $0 \cdot 41,1 \cdot 84)$; obese I $(\mathrm{HR}=1 \cdot 15$; 
Table 1 Baseline characteristics of participants by sex: men ( $n$ 94 133) and women ( $n$ 48 496) aged 35-59 years in 1990, Korea Medical Insurance Corporation study

\begin{tabular}{|c|c|c|c|c|c|c|c|c|c|c|c|c|c|c|c|c|c|c|c|c|}
\hline \multirow[b]{4}{*}{ Characteristic } & \multicolumn{20}{|c|}{ BMI $\left(\mathrm{kg} / \mathrm{m}^{2}\right)$} \\
\hline & \multicolumn{10}{|c|}{ Men } & \multicolumn{10}{|c|}{ Women } \\
\hline & \multicolumn{2}{|c|}{$\begin{array}{l}<18.5 \\
(n 974)\end{array}$} & \multicolumn{2}{|c|}{$\begin{array}{l}18.5-22.9 \\
(n 40254)\end{array}$} & \multicolumn{2}{|c|}{$\begin{array}{l}23 \cdot 0-24 \cdot 9 \\
(n 29369)\end{array}$} & \multicolumn{2}{|c|}{$\begin{array}{l}25 \cdot 0-29 \cdot 9 \\
(n 22946)\end{array}$} & \multicolumn{2}{|c|}{$\begin{array}{l}\geq 30.0 \\
(n 590)\end{array}$} & \multicolumn{2}{|c|}{$\begin{array}{c}<18.5 \\
(n 2199)\end{array}$} & \multicolumn{2}{|c|}{$\begin{array}{l}18.5-22 \cdot 9 \\
(n 29209)\end{array}$} & \multicolumn{2}{|c|}{$\begin{array}{l}23 \cdot 0-24 \cdot 9 \\
(n 11028)\end{array}$} & \multicolumn{2}{|c|}{$\begin{array}{c}25.0-29.9 \\
(n 5841)\end{array}$} & \multicolumn{2}{|c|}{$\begin{array}{l}\geq 30.0 \\
(n 219)\end{array}$} \\
\hline & $\begin{array}{l}\text { Mean } \\
\text { or } n\end{array}$ & $\begin{array}{l}\text { SD or } \\
\%\end{array}$ & $\begin{array}{l}\text { Mean } \\
\text { or } n\end{array}$ & $\begin{array}{l}\text { SD or } \\
\%\end{array}$ & $\begin{array}{l}\text { Mean } \\
\text { or } n\end{array}$ & $\begin{array}{l}\text { SD or } \\
\%\end{array}$ & $\begin{array}{l}\text { Mean } \\
\text { or } n\end{array}$ & $\begin{array}{l}\text { SD or } \\
\%\end{array}$ & $\begin{array}{l}\text { Mean } \\
\text { or } n\end{array}$ & $\begin{array}{c}\text { SD or } \\
\%\end{array}$ & $\begin{array}{l}\text { Mean } \\
\text { or } n\end{array}$ & $\begin{array}{l}\text { SD or } \\
\%\end{array}$ & $\begin{array}{l}\text { Mean } \\
\text { or } n\end{array}$ & $\begin{array}{l}\text { SD or } \\
\%\end{array}$ & $\begin{array}{l}\text { Mean } \\
\text { or } n\end{array}$ & $\begin{array}{c}\text { SD or } \\
\%\end{array}$ & $\begin{array}{l}\text { Mean } \\
\text { or } n\end{array}$ & $\begin{array}{l}\text { SD or } \\
\%\end{array}$ & $\begin{array}{l}\text { Mean } \\
\text { or } n\end{array}$ & $\begin{array}{c}\text { SD or } \\
\%\end{array}$ \\
\hline Age ( & $45 \cdot 6$ & 7.2 & 44 & 6. & 44.9 & 6.6 & 44.8 & 6 . & $45 \cdot 2$ & 6.7 & 39.6 & $5 \cdot 1$ & 41.0 & 5.5 & 43.4 & $6 \cdot 3$ & $45 \cdot 3$ & $6 \cdot 4$ & $46 \cdot 1$ & 6.7 \\
\hline $\mathrm{BMI}\left(\mathrm{kg} / \mathrm{m}^{2}\right)$ & 17.9 & 0.5 & 21.4 & $1 \cdot 1$ & 24.0 & 0.6 & $26 \cdot 4$ & 1.1 & 31.2 & 1.2 & $17 \cdot 8$ & 0.6 & 21.0 & 1.2 & 23.9 & 0.6 & $26 \cdot 4$ & 1.1 & 31.4 & 1.5 \\
\hline $\mathrm{SBP}(\mathrm{mmHg})$ & 118.7 & $12 \cdot 1$ & $122 \cdot 3$ & 13.0 & 125.9 & 13.6 & 128.9 & $14 \cdot 1$ & $135 \cdot \overline{7}$ & $15 \cdot 9$ & 110.9 & $10 \cdot 0$ & 113.8 & $10 \cdot 8$ & $118 \cdot 1$ & $12 \cdot 6$ & 123.0 & $14 \cdot 2$ & $132 \cdot 4$ & $17 \cdot 6$ \\
\hline $\mathrm{DBP}(\mathrm{mmHg})$ & $77 \cdot 2$ & 8.6 & 79.9 & 8.9 & 82.5 & 9.2 & 84.7 & 9.5 & 89.5 & $10 \cdot 5$ & $71 \cdot 6$ & 7.5 & $73 \cdot 8$ & $8 \cdot 0$ & $76 \cdot 9$ & $9 \cdot 0$ & $80 \cdot 3$ & 9.7 & $86 \cdot 5$ & 11.5 \\
\hline $\mathrm{FG}(\mathrm{mg} / \mathrm{dl})$ & $89 \cdot 2$ & 13.4 & $90 \cdot 3$ & $16 \cdot 3$ & 92.4 & 17.9 & 94.2 & 18.9 & $98 \cdot 2$ & 20.5 & $84 \cdot 1$ & $9 \cdot 8$ & 84.9 & $10 \cdot 0$ & $86 \cdot 9$ & $12 \cdot 3$ & $89 \cdot 1$ & 14.0 & $92 \cdot 6$ & 19.8 \\
\hline $\mathrm{TC}(\mathrm{mg} / \mathrm{dl})$ & $180 \cdot 3$ & $28 \cdot 4$ & $188 \cdot 2$ & 31.3 & $196 \cdot 4$ & 32.6 & $201 \cdot 3$ & 33.5 & $205 \cdot 6$ & 34.5 & $179 \cdot 1$ & $28 \cdot 2$ & 184.8 & $30 \cdot 3$ & 193.3 & $33 \cdot 2$ & $200 \cdot 8$ & 34.9 & 205.0 & 34.9 \\
\hline \multicolumn{21}{|l|}{ Smoking status ( $n, \%)$} \\
\hline Never smoker & 191 & $19 \cdot 6$ & 7785 & $19 \cdot 3$ & 6498 & $22 \cdot 1$ & 5435 & 23.7 & 148 & $25 \cdot 1$ & 2169 & 98.6 & 28868 & $98 \cdot 8$ & 10899 & $98 \cdot 8$ & 5746 & $98 \cdot 4$ & 214 & $97 \cdot 7$ \\
\hline Ex-smoker & 139 & $14 \cdot 3$ & 7683 & $19 \cdot 1$ & 6446 & $22 \cdot 0$ & 5224 & $22 \cdot 8$ & 127 & 21.5 & 17 & 0.8 & 237 & 0.8 & 88 & 0.8 & 67 & 1.2 & 1 & 0.5 \\
\hline Current smoker & 644 & $66 \cdot 1$ & 24786 & $61 \cdot 6$ & 16425 & 55.9 & 12287 & 53.6 & 315 & 53.4 & 13 & 0.6 & 104 & 0.4 & 41 & 0.4 & 28 & 0.5 & 4 & 1.8 \\
\hline$<20$ cigarettes/d & 456 & $46 \cdot 8$ & 17475 & 43.4 & 11147 & 38.0 & 7959 & 34.7 & 191 & $32 \cdot 4$ & 11 & 0.5 & 93 & 0.3 & 37 & 0.3 & 25 & 0.4 & 4 & $1 \cdot 8$ \\
\hline$\geq 20$ cigarettes $/ d$ & 188 & $19 \cdot 3$ & 7311 & $18 \cdot 2$ & 5278 & $18 \cdot 0$ & 4328 & $18 \cdot 9$ & 124 & $21 \cdot 0$ & 2 & 0.1 & 11 & 0.04 & 4 & 0.04 & 3 & 0.1 & 0 & 0.0 \\
\hline \multicolumn{21}{|c|}{ Alcohol consumption $(n, \%)$} \\
\hline No & 364 & 37.5 & 10231 & $25 \cdot 5$ & 6556 & $22 \cdot 4$ & 4819 & $21 \cdot 1$ & 139 & $23 \cdot 6$ & 2000 & $92 \cdot 5$ & 26184 & 90.5 & 9832 & $90 \cdot 2$ & 5064 & 87.9 & 182 & $84 \cdot 3$ \\
\hline Yes & 606 & $62 \cdot 5$ & 29906 & $74 \cdot 5$ & 22733 & $77 \cdot 6$ & 18067 & $78 \cdot 9$ & 451 & $76 \cdot 4$ & 163 & $7 \cdot 5$ & 2745 & 9.5 & 1068 & 9.8 & 700 & $12 \cdot 1$ & 34 & $15 \cdot 7$ \\
\hline \multicolumn{21}{|l|}{ Physical activity ( $n, \%)$} \\
\hline No & 746 & 78.0 & 27967 & $70 \cdot 5$ & 19484 & $67 \cdot 2$ & 15203 & $67 \cdot 1$ & 396 & $68 \cdot 3$ & 1900 & $86 \cdot 9$ & 24463 & $84 \cdot 3$ & 8995 & $82 \cdot 4$ & 4753 & $82 \cdot 4$ & 185 & $85 \cdot 3$ \\
\hline Yes & 210 & $22 \cdot 0$ & 11727 & 29.5 & 9507 & $32 \cdot 8$ & 7461 & $32 \cdot 9$ & 184 & $31 \cdot 7$ & 286 & $13 \cdot 1$ & 4563 & $15 \cdot 7$ & 1925 & $17 \cdot 6$ & 1019 & $17 \cdot 7$ & 32 & 14.8 \\
\hline
\end{tabular}

SBP, systolic blood pressure; DBP, diastolic blood pressure; FG, fasting glucose; TC, total cholesterol. 
Table 2 Hazard ratios for mortality according to BMI category by sex: men ( $n 94133$ ) and women ( $n 48496$ ) aged 35-59 years in 1990, follow-up period 1 January 1993 to 31 December 2006, Korea Medical Insurance Corporation study

\begin{tabular}{|c|c|c|c|c|}
\hline BMI $\left(\mathrm{kg} / \mathrm{m}^{2}\right)$ & No. of deaths & $\%$ of deaths & Adjusted HR* & Adjusted $95 \% \mathrm{Cl}^{*}$ \\
\hline \multicolumn{5}{|l|}{ Men } \\
\hline$<18.5$ & 93 & $9 \cdot 6$ & 1.48 & $1.21,1.82$ \\
\hline $18 \cdot 5-22 \cdot 9$ & 2440 & $6 \cdot 1$ & 1.00 & Reference \\
\hline $23 \cdot 0-24 \cdot 9$ & 1608 & 5.5 & 0.87 & $0.82,0.93$ \\
\hline $25 \cdot 0-29.9$ & 1222 & $5 \cdot 3$ & 0.86 & $0.80,0.91$ \\
\hline$\geq 30.0$ & 48 & $8 \cdot 1$ & 1.28 & $0.96,1.70$ \\
\hline \multicolumn{5}{|l|}{ Women } \\
\hline$<18.5$ & 31 & 1.4 & 1.20 & $0.83,1.74$ \\
\hline $18 \cdot 5-22.9$ & 393 & 1.4 & 1.00 & Reference \\
\hline $23 \cdot 0-24 \cdot 9$ & 189 & 1.7 & 1.03 & $0.86,1.23$ \\
\hline $25 \cdot 0-29 \cdot 9$ & 142 & 2.4 & 1.26 & $1.03,1.54$ \\
\hline$\geq 30.0$ & 7 & $3 \cdot 2$ & 1.55 & $0.73,3.29$ \\
\hline
\end{tabular}

$\mathrm{HR}$, hazard ratio.

${ }^{*}$ Adjusted for age and alcohol consumption.

$95 \%$ CI $0.96,1.36)$ and obese II (HR=1.98; $95 \%$ CI $1 \cdot 11$, 3.53) men showed a higher risk of mortality, with the association for obese I men being nearly significant. Among male ex-smokers, none of the BMI groups showed significantly increased mortality risk. Among male current smokers, being underweight was associated with a significantly higher risk of mortality ( $\mathrm{HR}=1.60 ; 95 \% \mathrm{CI} 1.28$, 2.01). Among female never smokers, being underweight was not significantly associated with mortality $(\mathrm{HR}=1 \cdot 12 ; 95 \% \mathrm{CI}$ $0.76,1.65)$; obese I ( $\mathrm{HR}=1.30 ; 95 \%$ CI 1.07, 1.60) women showed a significantly higher risk of mortality. Among female ex-smokers and current smokers, the number of deaths in each BMI category was too small to properly assess the relationship between BMI and mortality.

We additionally assessed cause-specific mortalities to investigate causes contributing to the increased mortality risk observed in underweight male participants who smoke cigarettes. Among male current smokers, being underweight was associated with an increased risk of death from cancer, respiratory disease and other causes, but not from CVD, compared with males with normal BMI (data presented in online supplementary material, Supplemental Table 1).

\section{Discussion}

In the present large-scale and long-term prospective study of middle-aged Korean men and women, no significant associations between being underweight and all-cause mortality were observed among never smokers.

Previous studies have reported that underweight people with disease or poor health exhibit different patterns of mortality than healthy underweight people. Moreover, underweight individuals with one of several prevalent diseases also show marked increases in mortality, compared with their normal-weight counterparts ${ }^{(22-24)}$. Thus, the inclusion of participants with underlying disease or poor health may limit analyses ${ }^{(8,10,11,25,26)}$. Accordingly, we excluded participants with underlying disease and those who died within the first 5 years of follow-up to reduce bias associated with reverse causality.

The physiological characteristics of smokers are not the same as those of the general population. In particular, smokers tend to have lower $\mathrm{BMI}^{(27)}$. Smoking is also one of the major leading risk factors for all-cause mortality worldwide ${ }^{(28,29)}$. Associations between BMI and mortality should therefore be separately analysed according to smoking status. Some prospective studies undertaken in Western and Chinese populations have suggested that mortality is not increased in never smokers of the lowest BMI category ${ }^{(2-9)}$. In contrast, other studies have found an increased risk of mortality in the leanest of participants who did not smoke ${ }^{(10,12-20)}$. There could be several explanations for this difference. First, participants with underlying diseases were not adequately excluded. In fact, some of the studies did not exclude participants with underlying disease ${ }^{(12-19)}$. Second, the validity of information on BMI may have been compromised. While repeated measurements can reduce measurement error, few of these previous studies measured height and weight twice. Third, the associations between being underweight and mortality could differ according to the age distribution of participants. Many studies included participants of ages 60 years or more ${ }^{(10,12-20)}$. These older participants may more likely carry co-morbidities, leading to low BMI and introducing bias to the results.

One previous study performed in Korea suggested that male never smokers $(\mathrm{HR}=1 \cdot 3 ; 95 \% \mathrm{CI} 1 \cdot 2,1.4)$ and ever smokers (HR $=1.4 ; 95 \%$ CI $1.3,1.4)$ with low BMI $\left(<18.5 \mathrm{~kg} / \mathrm{m}^{2}\right)$ exhibit higher mortality than reference males $\left(\mathrm{BMI}=23.0-24.9 \mathrm{~kg} / \mathrm{m}^{2}\right)$. Among female never smokers, those with low BMI showed higher mortality $(\mathrm{HR}=1 \cdot 2 ; 95 \% \mathrm{CI} 1 \cdot 1,1 \cdot 3)$ than the reference category ${ }^{(10)}$. We were unable to clearly determine what made our study findings different from those of the previous Korean study. 
The two studies are, nevertheless, distinct in a few aspects. First, the previous study enrolled insured workers and their family members of a wider age range (35-95 years) ${ }^{(10)}$, while our study enrolled only insured workers of ages 35 to 59 years. Second, the previous study enrolled participants who had undergone at least one health screening examination between 1992 and 1995, while our study enrolled participants who had undergone two health screening examinations in both 1990 and 1992, allowing us to use the means of two measurements for analysis to reduce measurement errors. Lastly, the reference categories were different: $B M I=23.0-24.9 \mathrm{~kg} / \mathrm{m}^{2}$ in the previous study and BMI $=18.5-22.9 \mathrm{~kg} / \mathrm{m}^{2}$ in our analysis.

Concerning current smokers, most previous studies have reported that underweight individuals are at a significantly increased risk of mortality $(2,9,10,12,13,16-18)$. This was also reflected in our results. We speculate that being thin may indicate a greater susceptibility to the adverse effects of smoking and particular smoking behaviours, such as deep inhalation.

The strengths of our study include the use of data from a large prospective study in Korea, which is, in general, a lean population. Second, we excluded participants with underlying disease or who died within the first 5 years of follow-up. Third, our study used average BMI, which was measured twice at baseline years (1990 and 1992); thus, our data on BMI might be more reliable and less subject to measurement error. Information on deaths was also accurate, since deaths were confirmed from the National Statistical Office via use of identification numbers assigned to participants at birth.

Our study has several limitations that warrant consideration. First, we performed the study in only middle-aged Korean men and women, which may limit the generalizability of our results to other populations. Nevertheless, our data from a population with a much lower average BMI than most Western populations enabled us to robustly explore associations that may not be prevalent in other cohorts. Second, a considerable number of women were excluded from the analysis, because they did not report their smoking status. If smoking women with poor health status were less likely to report their smoking status than healthy smoking women, selection bias might occur and distort our study findings. Notwithstanding, we did perform sensitivity analyses classifying participants with unknown smoking status into never smokers and the results were very close to our initial results. Third, we did not assess the effect of weight changes after baseline evaluation. If an underweight participant was to gain weight and a normal-weight participant was to lose weight, the difference in BMI between the two groups might become smaller. Thus, we could not completely exclude the possibility of a bias towards the null.

In conclusion, the present study does not support that being underweight per se is associated with higher mortality than being of normal weight. 


\section{Acknowledgements}

Acknowledgements: The authors thank the National Health Insurance Corporation (formerly the KMIC) for providing the data. Financial support: This research received no specific grant from any funding agency in the public, commercial or not-for-profit sectors. Conflict of interest: None. Authorship: J.Y.L. designed the study concepts, analysed the data and prepared the manuscript. H.C.K., C.K., S.V.A., K.P. and D.R.K. contributed to data analysis and interpretation. K.-T.K. and W.C.W. contributed to data analysis, data interpretation and revisions of the manuscript. I.S. collected the data, designed the study concepts, interpreted the data and edited the manuscript. All investigators contributed to the final version of the report. Ethics of human subject participation: This study was approved by the Institutional Review Board of the Severance Hospital at Yonsei University.

\section{Supplementary material}

To view supplementary material for this article, please visit http://dx.doi.org/10.1017/S136898001500302X

\section{References}

1. Flegal KM, Kit BK, Orpana $\mathrm{H}$ et al. (2013) Association of all-cause mortality with overweight and obesity using standard body mass index categories: a systematic review and meta-analysis. JAMA 309, 71-82.

2. Chen Z, Yang G, Offer A et al. (2012) Body mass index and mortality in China: a 15 -year prospective study of 220000 men. Int J Epidemiol 41, 472-481.

3. Ma J, Flanders WD, Ward EM et al. (2011) Body mass index in young adulthood and premature death: analyses of the US National Health Interview Survey linked mortality files. Am J Epidemiol 174, 934-944.

4. Moore SC, Mayne ST, Graubard BI et al. (2008) Past body mass index and risk of mortality among women. Int J Obes (Lond) 32, 730-739.

5. Freedman DM, Ron E, Ballard-Barbash R et al. (2006) Body mass index and all-cause mortality in a nationwide US cohort. Int J Obes (Lond) 30, 822-829.

6. Hjartaker A, Adami HO, Lund E et al. (2005) Body mass index and mortality in a prospectively studied cohort of Scandinavian women: the women's lifestyle and health cohort study. Eur J Epidemiol 20, 747-754.

7. Stevens J, Cai J, Pamuk ER et al. (1998) The effect of age on the association between body-mass index and mortality. $N$ Engl J Med 338, 1-7.

8. Manson JE, Willett WC, Stampfer MJ et al. (1995) Body weight and mortality among women. $N$ Engl J Med 333, 677-685.

9. Arndt V, Rothenbacher D, Zschenderlein B et al. (2007) Body mass index and premature mortality in physically heavily working men - a ten-year follow-up of 20,000 construction workers. J Occup Environ Med 49, 913-921.

10. Jee SH, Sull JW, Park J et al. (2006) Body-mass index and mortality in Korean men and women. $N$ Engl J Med 355, 779-787.
11. Zheng W, McLerran DF, Rolland B et al. (2011) Association between body-mass index and risk of death in more than 1 million Asians. $N$ Engl J Med 364, 719-729.

12. Song X, Pitkaniemi J, Gao W et al. (2012) Relationship between body mass index and mortality among Europeans. Eur J Clin Nutr 66, 156-165.

13. Sasazuki S, Inoue M, Tsuji I et al. (2011) Body mass index and mortality from all causes and major causes in Japanese: results of a pooled analysis of 7 large-scale cohort studies. J Epidemiol 21, 417-430.

14. Berrington de Gonzalez A, Hartge P, Cerhan JR et al. (2010) Body-mass index and mortality among 1.46 million white adults. $N$ Engl J Med 363, 2211-2219.

15. Bessonova L, Marshall SF, Ziogas A et al. (2011) The association of body mass index with mortality in the California Teachers Study. Int J Cancer 129, 2492-2501.

16. Klenk J, Nagel G, Ulmer H et al. (2009) Body mass index and mortality: results of a cohort of 184,697 adults in Austria. Eur J Epidemiol 24, 83-91.

17. Adams KF, Schatzkin A, Harris TB et al. (2006) Overweight, obesity, and mortality in a large prospective cohort of persons 50 to 71 years old. N Engl J Med 355, 763-778.

18. Hayashi R, Iwasaki M, Otani T et al. (2005) Body mass index and mortality in a middle-aged Japanese cohort. J Epidemiol 15, 70-77.

19. $\mathrm{Hu} \mathrm{G}$, Tuomilehto J, Silventoinen $\mathrm{K}$ et al. (2005) The effects of physical activity and body mass index on cardiovascular, cancer and all-cause mortality among 47212 middle-aged Finnish men and women. Int J Obes (Lond) 29, 894-902.

20. Flegal KM, Kit BK \& Graubard BI (2014) Body mass index categories in observational studies of weight and risk of death. Am J Epidemiol 180, 288-296.

21. World Health Organization/International Association for the Study of Obesity/International Obesity Task Force (2000) The Asia-Pacific Perspective: Redefining Obesity and Its Treatment. Melbourne: Health Comminications Australia.

22. Sharma A, Vallakati A, Einstein AJ et al. (2014) Relationship of body mass index with total mortality, cardiovascular mortality, and myocardial infarction after coronary revascularization: evidence from a meta-analysis. Mayo Clin Proc 89, 1080-1100.

23. Schlesinger S, Siegert S, Koch M et al. (2014) Postdiagnosis body mass index and risk of mortality in colorectal cancer survivors: a prospective study and meta-analysis. Cancer Causes Control 25, 1407-1418.

24. Li T, Liu J, An S et al. (2014) Body mass index and mortality in patients on maintenance hemodialysis: a meta-analysis. Int Urol Nephrol 46, 623-631.

25. Zhang X, Shu XO, Chow WH et al. (2008) Body mass index at various ages and mortality in Chinese women: impact of potential methodological biases. Int J Obes (Lond) 32, $1130-1136$.

26. Hu FB, Willett WC, Li T et al. (2004) Adiposity as compared with physical activity in predicting mortality among women. N Engl J Med 351, 2694-2703.

27. Yanbaeva DG, Dentener MA, Creutzberg EC et al. (2007) Systemic effects of smoking. Chest 131, 1557-1566.

28. Lopez AD, Mathers CD, Ezzati M et al. (2006) Global and regional burden of disease and risk factors, 2001: systematic analysis of population health data. Lancet $\mathbf{3 6 7}$, $1747-1757$.

29. Ezzati M, Lopez AD, Rodgers A et al. (2002) Selected major risk factors and global and regional burden of disease. Lancet 360, 1347-1360. 